\title{
Treatment of the High Concentration Nonylphenol Ethoxylates (NPEOs) Wastewater by Fenton Oxidation Process
}

\author{
Ruoyu Zhou, Wenqi Zhang* \\ College of Chemistry and Chemical Engineering, Shanghai University of Engineering Science, Shanghai, China \\ Email: *zhangwenqi_hit@163.com
}

How to cite this paper: Zhou, R.Y. and Zhang, W.Q. (2017) Treatment of the High Concentration Nonylphenol Ethoxylates (NPEOs) Wastewater by Fenton Oxidation Process. American Journal of Analytical Chemistry, 8, 72-80.

http://dx.doi.org/10.4236/ajac.2017.81006

Received: December 12, 2016

Accepted: January 9, 2017

Published: January 12, 2017

Copyright $\odot 2017$ by authors and Scientific Research Publishing Inc. This work is licensed under the Creative Commons Attribution International License (CC BY 4.0).

http://creativecommons.org/licenses/by/4.0/

\begin{abstract}
The Fenton oxidation process was applied in the treatment of an actual high concentration nonylphenol Ethoxylates (NPEOs) wastewater. The effects of $\mathrm{H}_{2} \mathrm{O}_{2}$ dosage, molar ratio of $\mathrm{H}_{2} \mathrm{O}_{2} / \mathrm{Fe}^{2+}$ ( $\mathrm{Fe}^{2+}$ dosage), $\mathrm{pH}$ value and reaction time on the degradation of NPEOs were investigated. The orthogonal experiment indicated that the order of degree of influence on the COD removal was molar ratio of $\mathrm{H}_{2} \mathrm{O}_{2} / \mathrm{Fe}^{2+}$, reaction time, dosage of $\mathrm{H}_{2} \mathrm{O}_{2}$, and initial $\mathrm{pH}$. The single-factor tests were carried out to determine the optimal conditions, and the results were $\mathrm{H}_{2} \mathrm{O}_{2}$ dosage of $76.32 \mathrm{mmol} / \mathrm{L}$, molar ratio of $\mathrm{H}_{2} \mathrm{O}_{2} / \mathrm{Fe}^{2+}$ of 3 , $\mathrm{pH}$ value of 5 and reaction time of $2 \mathrm{~h}$. Under the optimum operation conditions, the COD removal efficiency was $85.6 \%$ and the effluent could be mixed with other wastewater into the large-scale biological treatment system.
\end{abstract}

\section{Keywords}

Fenton, Nonylphenol Ethoxylates, Orthogonal Experiment, Single-Factor

\section{Introduction}

Nonylphenolethoxylates (NPEOs) are a group of nonionic surfactants that are most often used in detergents, emulsifiers, and dispersing agents in household, agricultural, and industrial applications [1]. As a consequence of the extensive use, discharge of NPEOs occurs in the environment via industrial effluents and domestic sewage. NPEOs can be biodegraded to generate nonylphenol (NP) and short chain NPEOs which are more toxic, more lipophilic and more persistent than the parent substance [2] [3].

Low concentration NPEOs in water environment can be treated by biological [4], advanced oxidation [5] [6], photocatalytic [7] and adsorption [8] methods. 
However, although high concentration NPEOs wastewater is discharged by factories, very few data is available on the treatment of industrial effluent. The presence of high concentration NPEOs in biological treatment plants may cause serious problems, such as production of a large amount of foams, the loss of microorganisms in bio-reactor. In some enterprises, this wastewater is often treated by the distillation process, which is not only costly, but also produces a lot of higher concentration of NPEOs waste liquid. New environmental problems have been produced.

Fenton is a simple and effective process for industrial wastewater treatment. In this process, hydrogen peroxide is added to wastewater in presence of ferrous salt, generating species that are strongly oxidative with respect to organic compounds present. Hydroxyl radicals $(\cdot \mathrm{OH})$ are traditionally regarded as the key oxidizing species in the Fenton processes, though high valence iron species and alkoxyl radicals have also been proposed. The classical Fenton free radical mechanism in the absence of organic compounds mainly involves the sequence of reactions below. [9] [10] [11] [12]

$$
\begin{aligned}
& \mathrm{Fe}^{2+}+\mathrm{H}_{2} \mathrm{O}_{2} \rightarrow \mathrm{Fe}^{3+}+\cdot \mathrm{OH}+\mathrm{OH}^{-} \\
& \mathrm{Fe}^{3+}+\mathrm{H}_{2} \mathrm{O}_{2} \rightarrow \mathrm{Fe}^{2+}+\cdot \mathrm{OOH}+\mathrm{H}^{+} \\
& \cdot \mathrm{OH}+\mathrm{H}_{2} \mathrm{O}_{2} \rightarrow \cdot \mathrm{OOH}+\mathrm{H}_{2} \mathrm{O} \\
& \cdot \mathrm{OH}+\mathrm{Fe}^{2+} \rightarrow \mathrm{Fe}^{3+}+\mathrm{OH}^{-} \\
& \mathrm{Fe}^{3+}+\cdot \mathrm{OOH} \rightarrow \mathrm{Fe}^{2+}+\mathrm{O}_{2} \mathrm{H}^{+} \\
& \mathrm{Fe}^{2+}+\cdot \mathrm{OOH}+\mathrm{H}^{+} \rightarrow \mathrm{Fe}^{3+}+\mathrm{H}_{2} \mathrm{O}_{2} \\
& 2 \mathrm{OOH} \rightarrow \mathrm{H}_{2} \mathrm{O}_{2}+\mathrm{O}_{2}
\end{aligned}
$$

Although $\mathrm{Fe}^{3+}$ can be reduced to $\mathrm{Fe}^{2+}$ through Equation (2), the rate is several orders of magnitude slower than that of $\mathrm{Fe}^{2+}-\mathrm{Fe}^{3+}$ conversion through Equation (1). And the formed $\mathrm{Fe}^{3+}$ may precipitate to iron hydroxides, particularly as $\mathrm{pH}$ is increased.

In this study we have evaluated reactions of Fenton's reagent with high concentration NPEOs wastewater. Various parameters, including $\mathrm{pH}, \mathrm{Fe}^{2+}$ and $\mathrm{H}_{2} \mathrm{O}_{2}$ dosages, reaction time, have been fully discussed. The optimal reaction conditions have been determined.

\section{Experimental Section}

\subsection{Chemicals}

The $\mathrm{NP}_{\mathrm{n}} \mathrm{EO}\left[\mathrm{n}=10\left(\mathrm{NP}_{10} \mathrm{EO}\right)\right]$ wastewater was obtained from a chemical enterprise in China. The COD of this actual wastewater was $12,000 \pm 500 \mathrm{mg} / \mathrm{L}$ and its $\mathrm{pH}$ was about 6.5. All chemicals were purchased from Sinopharm Chemical Reagent Co., Ltd. (China).

\subsection{Experimental Procedure}

The Fenton process started when the required $\mathrm{FeSO}_{4}$ dosage was added into the 
beaker containing $100 \mathrm{~mL}$ wastewater, stirred by a magnetic stirrer with a desired speed $(300 \mathrm{rpm})$. In addition, the initial $\mathrm{pH}$ of the wastewater was adjusted by adding diluted sulfuric acid $(1 \mathrm{~mol} / \mathrm{L})$ or sodium hydroxide solutions (1 mol/L), then quickly added quantitative $\mathrm{H}_{2} \mathrm{O}_{2}$. Samples were collected after $2 \mathrm{~h}$ unless otherwise noted. And COD of each sample was measured after sedimentation. All experiments were performed at ambient temperature.

\subsection{Orthogonal Experimental Design}

Depending on the reaction mechanism of Fenton reaction, four parameters of $\mathrm{H}_{2} \mathrm{O}_{2}$ dosage (A), $\mathrm{H}_{2} \mathrm{O}_{2} / \mathrm{Fe}^{2+}$ molar ratio (B), initial $\mathrm{pH}(\mathrm{C})$ and reaction time (D) were selected as influencing factors in the orthogonal experiment. Three levels were selected for each factor (shown in Table 1).

\subsection{Analytical Methods}

Chemical oxygen demand (COD) was determined by potassium dichromate method according to Standard Methods. The $\mathrm{pH}$ was measured by a PHS-2F pH meter.

\section{Results and Discussion}

\subsection{Results of Orthogonal Experiment}

The results of the orthogonal experiment were shown in Table 2.

As can be seen from the orthogonal experiment and range analysis, the order of degree of influence on the COD removal rate was molar ratio of $\mathrm{H}_{2} \mathrm{O}_{2} / \mathrm{Fe}^{2+}$, reaction time, dosage of $\mathrm{H}_{2} \mathrm{O}_{2}$, and the initial $\mathrm{pH}$. In this orthogonal experiment, when the initial COD concentration was $12000 \mathrm{mg} / \mathrm{L}$, the optimal reaction conditions were determined: $\mathrm{H}_{2} \mathrm{O}_{2}$ dosage $76.32 \mathrm{mmol} / \mathrm{L}$, the molar ratio of 2 and initial $\mathrm{pH}$ of 5.0. The reaction time was $1 \mathrm{~h}$.

\subsection{Single Factor Experiment}

In order to determine the most optimal conditions, single factor experiments were analyzed after orthogonal experiment.

\subsubsection{Effect of Initial pH}

According to the results of orthogonal experiment and relevant literatures [13]

Table 1. Factors and levels of orthogonal experiment.

\begin{tabular}{ccccc}
\hline & Factor A & Factor B & Factor C & Factor D \\
\cline { 2 - 5 } Parameters & $\begin{array}{c}\mathrm{H}_{2} \mathrm{O}_{2} \text { dosage } \\
(\mathrm{mmol} / \mathrm{L})\end{array}$ & $\begin{array}{c}{\left[\mathrm{H}_{2} \mathrm{O}_{2}\right] /\left[\mathrm{Fe}^{2+}\right]} \\
(\text { molar ratio })\end{array}$ & Initial pH & $\begin{array}{c}\text { Reaction time } \\
(\mathrm{h})\end{array}$ \\
\hline Labels & $\mathrm{A}$ & $\mathrm{B}$ & $\mathrm{C}$ & $\mathrm{D}$ \\
Level 1 & 57.24 & 2 & 3 & 0.5 \\
Level 2 & 66.78 & 3 & 4 & 1 \\
Level 3 & 76.32 & 4 & 5 & 2
\end{tabular}


[14], selected $\mathrm{H}_{2} \mathrm{O}_{2}$ dosage of $76.32 \mathrm{mmol} / \mathrm{L}$, molar ratio of $\mathrm{H}_{2} \mathrm{O}_{2} / \mathrm{Fe}^{2+}$ of 3 , reaction time of $2 \mathrm{~h}$, and the effect of initial $\mathrm{pH}$ on COD removal were investigated (shown in Figure 1).

As shown in Figure 1, there was a significant impact of $\mathrm{pH}$ on the COD removal. The optimal initial $\mathrm{pH}$ was 5 , the COD removal reached highest with $83.5 \%$. When the initial $\mathrm{pH}$ of the wastewater was increased from 6 to 7 , the COD removal significantly reduced. It might be because that the reaction system generated $\mathrm{Fe}^{2+}$ and $\mathrm{Fe}^{3+}$ hydroxide, while inhibiting the $\mathrm{Fe}^{2+}$ catalysis, reducing

Table 2. Results of orthogonal experiment and range analysis.

\begin{tabular}{|c|c|c|c|c|c|}
\hline $\begin{array}{c}\text { Experiment } \\
\text { Number }\end{array}$ & Factor A & Factor B & Factor $\mathrm{C}$ & Factor D & $\begin{array}{c}\text { COD removal } \\
\%\end{array}$ \\
\hline 1 & 1 & 1 & 1 & 1 & 52.5 \\
\hline 2 & 1 & 2 & 2 & 2 & 82.2 \\
\hline 3 & 1 & 3 & 3 & 3 & 18.2 \\
\hline 4 & 2 & 1 & 2 & 3 & 79.1 \\
\hline 5 & 2 & 2 & 3 & 1 & 69.0 \\
\hline 6 & 2 & 3 & 1 & 2 & 62.1 \\
\hline 7 & 3 & 1 & 3 & 2 & 83.8 \\
\hline 8 & 3 & 2 & 1 & 3 & 82.7 \\
\hline 9 & 3 & 3 & 2 & 1 & 42.9 \\
\hline $\mathrm{K}_{1}$ & 152.9 & 215.4 & 197.3 & 164.4 & \\
\hline $\mathrm{K}_{2}$ & 210.2 & 233.9 & 204.2 & 228.1 & \\
\hline $\mathrm{K}_{3}$ & 209.4 & 123.2 & 171 & 180 & \\
\hline $\mathrm{k}_{1}$ & 51 & 71.8 & 65.8 & 54.8 & \\
\hline $\mathrm{k}_{2}$ & 70.1 & 78 & 68.1 & 76 & \\
\hline $\mathrm{k}_{3}$ & 69.8 & 41.1 & 57 & 60 & \\
\hline $\mathrm{R}$ & 19.1 & 36.9 & 11.1 & 21.2 & \\
\hline
\end{tabular}

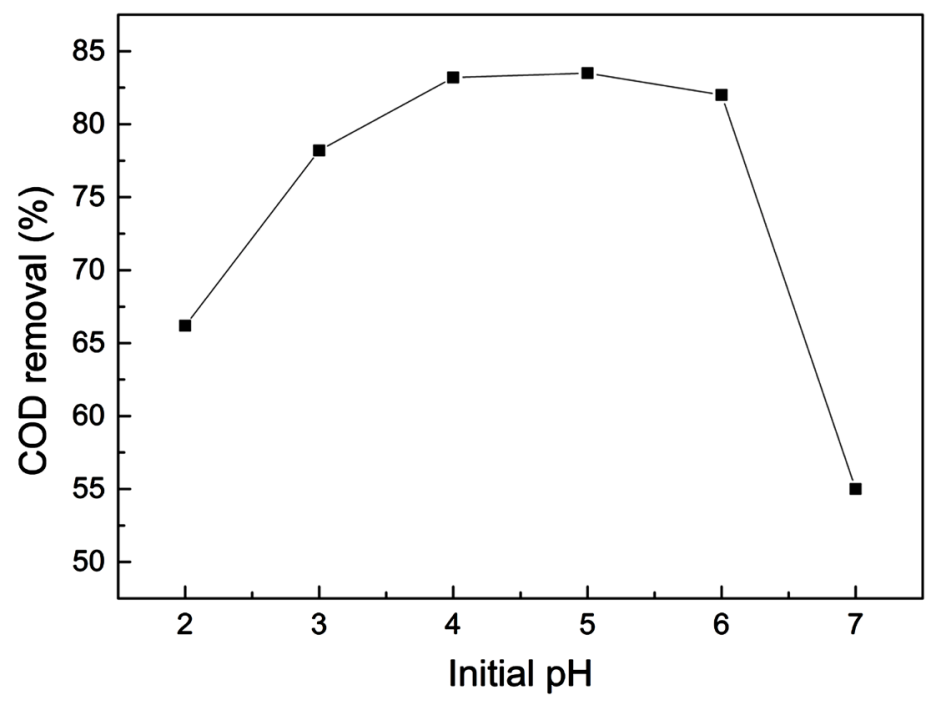

Figure 1. Effect of initial $\mathrm{pH}$ on the treatment efficiencies of the Fenton process. 
the production rate of $\cdot \mathrm{OH}$. [12] When the $\mathrm{pH}$ was less than 3, the Fenton reagent oxidation was also inhibited. This might be due to the plenty of $\mathrm{H}^{+}$reacted with $\mathrm{H}_{2} \mathrm{O}_{2}$, generation $\left[\mathrm{H}_{3} \mathrm{O}_{2}\right]^{+}$which was more stable and inhibited the production of $\cdot \mathrm{OH}$ [15]. In addition, the excess of $\mathrm{H}^{+}$would react with $\cdot \mathrm{OH}$, thereby reducing the oxidation Fenton reagent [16].

In this study, the efficiency of COD removal was still high when the initial $\mathrm{pH}$ was 6 . But the $\mathrm{pH}$ of all effluent after Fenton process was less than 3. This showed that the $\mathrm{pH}$ of the wastewater was decreasing in the reaction process which may be due to the production of some intermediate products, such as nonylphenoxy carboxylic acids (NPEC) [17] [18]. It was speculated that the optimal $\mathrm{pH}$ in reaction process was still in the range of $3-4$, which was coincident with the values reported in the literatures.

\subsubsection{Effect of $\mathrm{H}_{2} \mathrm{O}_{2}$ Dosage}

Selected molar ratio of $\mathrm{H}_{2} \mathrm{O}_{2} / \mathrm{Fe}^{2+}$ of 3 , reaction time of $2 \mathrm{~h}$, the initial $\mathrm{pH}$ of 5 , and the effect of $\mathrm{H}_{2} \mathrm{O}_{2}$ dosage on COD removal was investigated, the test results were shown in Figure 2.

It could be seen from Figure 2, with the amount of $\mathrm{H}_{2} \mathrm{O}_{2}$ from $9.53 \mathrm{mmol} / \mathrm{L}$ to $47.7 \mathrm{mmol} / \mathrm{L}$, COD removal quickly increased from $5.4 \%$ to $80.1 \%$. Increasing the dosage of $\mathrm{H}_{2} \mathrm{O}_{2}$ to $85.86 \mathrm{mmoI} / \mathrm{L}$, the efficiency of COD removal grew slowed slightly. When the $\mathrm{H}_{2} \mathrm{O}_{2}$ concentration was higher than $85.86 \mathrm{mmol} / \mathrm{L}$, the removal rate decreased slightly instead of increasing. This could be seen from the Equation (3), when the $\mathrm{H}_{2} \mathrm{O}_{2}$ dosage was large, the excess of $\mathrm{H}_{2} \mathrm{O}_{2}$ had quenching effect with the generation of $\cdot \mathrm{OH}$ [19]. Therefore, the optimal dosage of $\mathrm{H}_{2} \mathrm{O}_{2}$ was determined as $76.32 \mathrm{mmol} / \mathrm{L}$.

\subsubsection{Effect of Reaction Time}

Figure 3 showed the effect of reaction time on COD removal in the condition of $\mathrm{H}_{2} \mathrm{O}_{2}$ dosage of $76.32 \mathrm{mmol} / \mathrm{L}$, molar ratio of $\mathrm{H}_{2} \mathrm{O}_{2} / \mathrm{Fe}^{2+}$ of 3 , the initial $\mathrm{pH}$ of 5 .

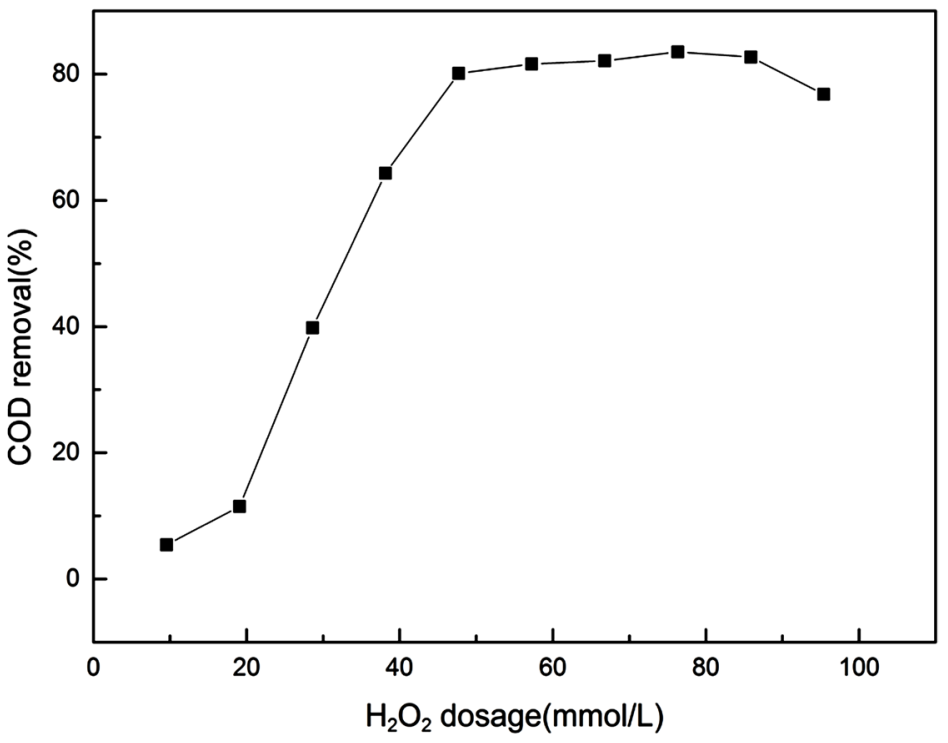

Figure 2. Effect of $\mathrm{H}_{2} \mathrm{O}_{2}$ dosage on the treatment efficiencies of the Fenton process. 
It could be seen form Figure 3 that in the first $1.5 \mathrm{~h}$, COD removal increased significantly with the reaction time, then stabilized at $76.9 \%-84.1 \%$. The reaction time of $2 \mathrm{~h}$ was preferably selected.

\subsubsection{Effect of Molar Ratio of $\mathrm{H}_{2} \mathrm{O}_{2} / \mathrm{Fe}^{2+}$}

$\mathrm{Fe}^{2+}$ was a necessary condition to produce $\cdot \mathrm{OH}$, since in Fenton reaction the rate of $\mathrm{Fe}^{3+}$ restoring to $\mathrm{Fe}^{2+}$ was very slow, the concentration of $\mathrm{Fe}^{2+}$ determined the amount of generation of $\cdot \mathrm{OH}$. Selected $\mathrm{H}_{2} \mathrm{O}_{2}$ dosage of $76.32 \mathrm{mmol} / \mathrm{L}$, reaction time of $2 \mathrm{~h}$, the initial $\mathrm{pH}$ of 5 , and the effect of molar ratio of $\mathrm{H}_{2} \mathrm{O}_{2} / \mathrm{Fe}^{2+}$ on COD removal was investigated, the test results shown in Figure 4.

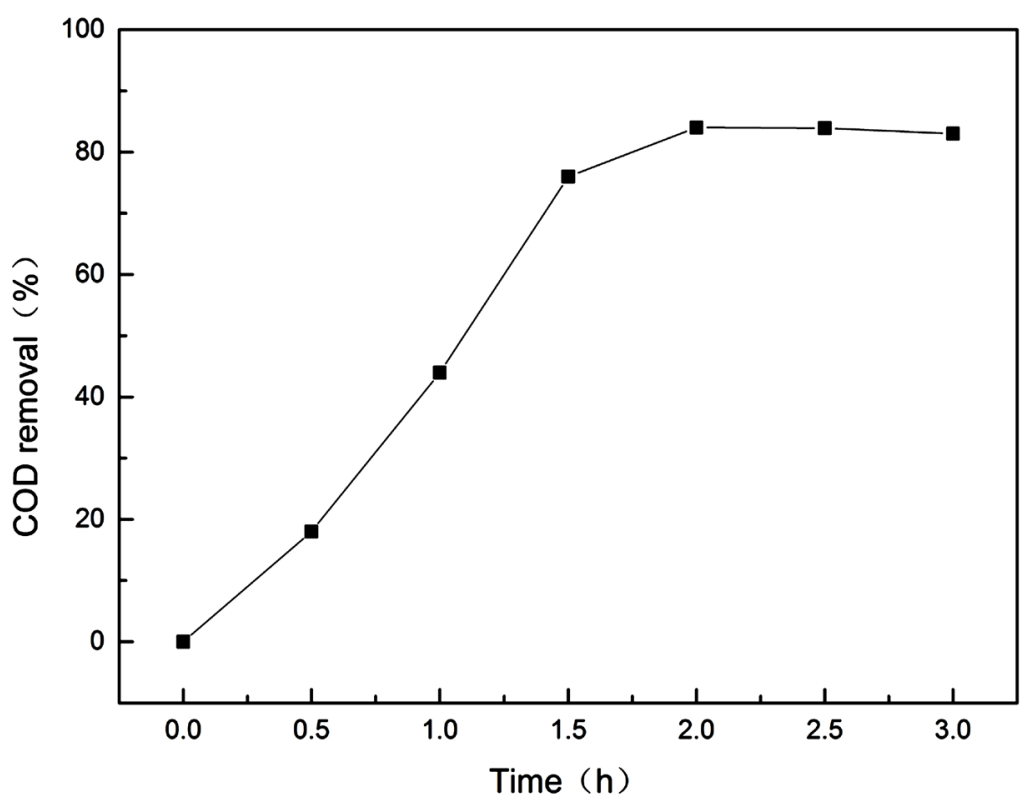

Figure 3. Effect of reaction time on the treatment efficiencies of the Fenton process.

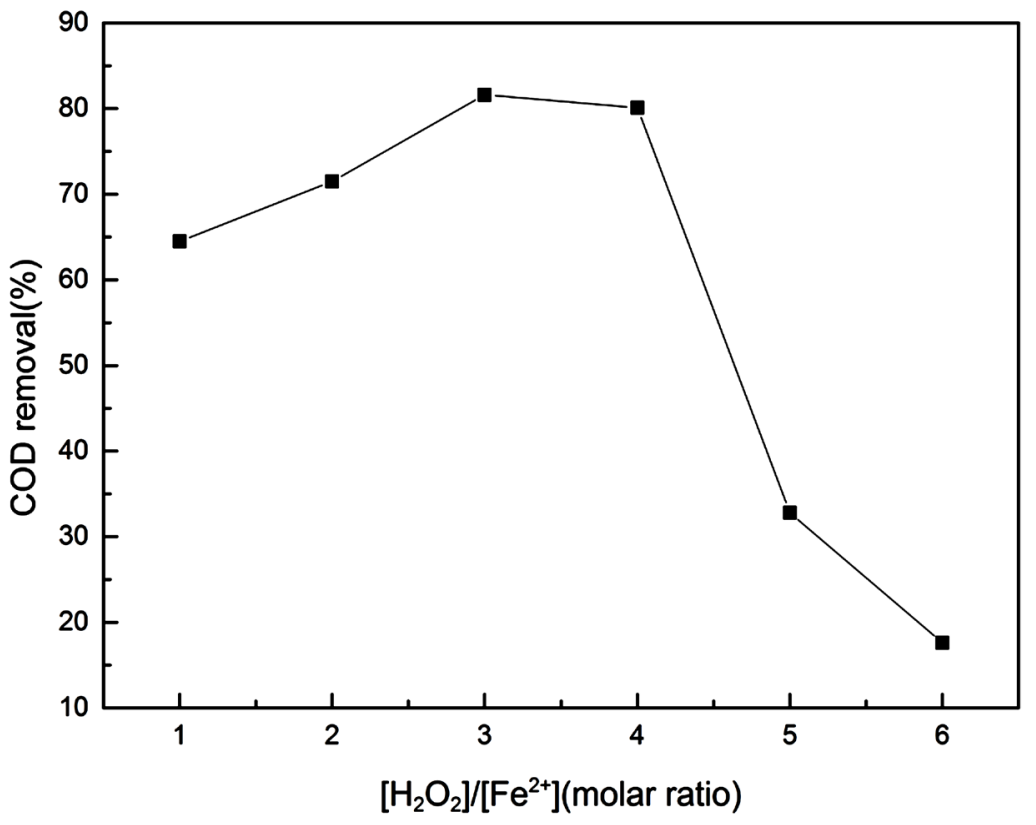

Figure 4. Effect of $\left[\mathrm{H}_{2} \mathrm{O}_{2}\right] /\left[\mathrm{Fe}^{2+}\right]$ on the treatment efficiencies of the Fenton process. 
As can be seen from Figure 4, with the molar ratio of $\mathrm{H}_{2} \mathrm{O}_{2} / \mathrm{Fe}^{2+}$ increased (the concentration of $\mathrm{Fe}^{2+}$ decreased), the efficiency of COD removal increased from $64.5 \%$ to $80.1 \%$. Continued to reduce the dosage of $\mathrm{Fe}^{2+}$, the COD removal reduced. When the molar ratio of $\mathrm{H}_{2} \mathrm{O}_{2} / \mathrm{Fe}^{2+}$ increased to 6, the COD removal rate was only $17.6 \%$. The phenomenon was consistent with other research results.

The appropriate molar ratio of $\mathrm{H}_{2} \mathrm{O}_{2} / \mathrm{Fe}^{2+}$ could promote Equation (1), generating $\cdot \mathrm{OH}$ quickly. When the molar ratio of $\mathrm{H}_{2} \mathrm{O}_{2} / \mathrm{Fe}^{2+}$ was too low (the $\mathrm{Fe}^{2+}$ concentration was too high), it would promote the Equation (4), resulting in the consumption of $\cdot \mathrm{OH}$ to reduce the rate of the reaction. When the molar ratio of $\mathrm{H}_{2} \mathrm{O}_{2} / \mathrm{Fe}^{2+}$ was too high (the $\mathrm{Fe}^{2+}$ concentration was too low), the generation of $\cdot \mathrm{OH}$ was very limited and the $\mathrm{COD}$ removal was reduced. Therefore, the optimum molar ratio of $\mathrm{H}_{2} \mathrm{O}_{2} / \mathrm{Fe}^{2+}$ was 3 .

\subsection{The Optimum Condition}

From the orthogonal experiment and the single-factor experiment, we determined the optimum conditions: $\mathrm{H}_{2} \mathrm{O}_{2}$ dosage of $76.32 \mathrm{mmol} / \mathrm{L}$, molar ratio of $\mathrm{H}_{2} \mathrm{O}_{2} / \mathrm{Fe}^{2+}$ of $3, \mathrm{pH}$ value of 5 and reaction time of $2 \mathrm{~h}$. Under the optimum conditions, the repeatable experiments of the NPEOs wastewater by Fenton oxidation process had been carried out 10 times. And the average COD removal rate was $85.6 \%$.

\section{Conclusions}

Fenton oxidation of Nonylphenol Ethoxylate-10 $\left(\mathrm{NP}_{10} \mathrm{EOs}\right)$ in actual wastewater was investigated. Orthogonal experiment and single factor experiments were carried out to assess the optimum condition leading to the maximum removal of the surfactants. The main results obtained during the investigation were the following:

The orthogonal experiment indicated that the order of degree of influence on the COD removal rate was molar ratio of $\mathrm{H}_{2} \mathrm{O}_{2} / \mathrm{Fe}^{2+}$, reaction time, dosage of $\mathrm{H}_{2} \mathrm{O}_{2}$, and initial $\mathrm{pH}$.

The single-factor tests were carried out to determine the optimal conditions: $\mathrm{H}_{2} \mathrm{O}_{2}$ dosage of $76.32 \mathrm{mmol} / \mathrm{L}$, molar ratio of $\mathrm{H}_{2} \mathrm{O}_{2} / \mathrm{Fe}^{2+}$ of 3 , $\mathrm{pH}$ value of 5 and reaction time of $2 \mathrm{~h}$. Under the optimum operation conditions, the average COD removal rate was $85.6 \%$.

\section{Acknowledgements}

This study was financially supported by Shanghai University of Engineering Science Innovation Fund for Graduate Students (No: E1-0903-15-01035).

\section{References}

[1] Soares, A., Guieysse, B., Jefferson, B., Cartmell, E. and Lester, J.N. (2008) Nonylphenol in the Environment: A Critical Review on Occurrence, Fate, Toxicity and Treatment in Wastewaters. Environment international, 34, 1033-1049.

https://doi.org/10.1016/j.envint.2008.01.004 
[2] Ying, G.G. (2006) Fate, Behavior and Effects of Surfactants and Their Degradation Products in the Environment. Environment International, 32, 417-431. https://doi.org/10.1016/j.envint.2005.07.004

[3] Sharma, V.K., Anquandah, GAK, Yngard, R.A., et al. (2009) Nonylphenol, Octylphenol, and Bisphenol-A in the Aquatic Environment: A Review on Occurrence, Fate, and Treatment. Journal of Environmental Science and Health, Part A, 44, 423 442. https://doi.org/10.1080/10934520902719704

[4] Lu, J., Jin, Q., He, Y. and Wu, J. (2007) Biodegradation of Nonylphenol Polyethoxylates under Fe(III)-Reducing Conditions. Chemosphere, 69, 1047-1054. https://doi.org/10.1016/j.chemosphere.2007.04.035

[5] Karci, A., Arslan-Alaton, I., Bekbolet, M., Ozhan, G. and Alpertunga, B. (2014) $\mathrm{H}_{2} \mathrm{O}_{2}$ /UV-C and Photo-Fenton Treatment of a Nonylphenol Polyethoxylate in Synthetic Freshwater: Follow-Up of Degradation Products, Acute Toxicity and Genotoxicity. Chemical Engineering Journal, 241, 43-51. https://doi.org/10.1016/j.cej.2013.12.022

[6] Pagano, M., Lopez, A., Volpe, A., Mascolo, G. and Ciannarella, R. (2008) Oxidation of Nonionic Surfactants by Fenton and $\mathrm{H}_{2} \mathrm{O}_{2} / \mathrm{UV}$ Processes. Environmental Technology, 29, 423-433. https://doi.org/10.1080/09593330801983862

[7] Chen, L., Zhou, H.Y., Liu, L. and Deng, Q.Y. (2007) Mechanism Study on UVInduced Photodegradation of Nonylphenol Ethoxylates by Intermediate Products Analysis. Chinese Chemical Letters, 18, 473-475. https://doi.org/10.1016/j.cclet.2007.02.004

[8] Liu, G., Zheng, S., Yin, D., Xu, Z., Fan, J. and Jiang, F. (2006) Adsorption of Aqueous Alkylphenol Ethoxylate Surfactants by Mesoporous Carbon CMK-3. Journal of Colloid and Interface Science, 302, 47-53. https://doi.org/10.1016/j.jcis.2006.06.006

[9] Tang, W.Z. and Huang, C.P. (1996) 2, 4-Dichlorophenol Oxidation Kinetics by Fenton's Reagent. Environmental Technology, 17, 1371-1378. https://doi.org/10.1080/09593330.1996.9618465

[10] Jung, Y.S., Lim, W.T., Park, J.Y. and Kim, Y.H. (2009) Effect of pH on Fenton and Fenton-Like Oxidation. Environmental Technology, 30, 183-190. https://doi.org/10.1080/09593330802468848

[11] Pignatello, J.J., Oliveros, E. and MacKay, A. (2006) Advanced Oxidation Processes for Organic Contaminant Destruction Based on the Fenton Reaction and Related Chemistry. Critical Reviews in Environmental Science and Technology, 36, 81-84. https://doi.org/10.1080/10643380500326564

[12] Neyens, E. and Baeyens, J. (2003) A Review of Classic Fenton's Peroxidation as an Advanced Oxidation Technique. Journal of Hazardous Materials, 98, 33-50. https://doi.org/10.1016/S0304-3894(02)00282-0

[13] Kitis, M., Adams, C.D. and Daigger, G.T. (1999) TheEffects of Fenton's Reagent Pretreatment on the Biodegradability of Nonionic Surfactants. Water Research, 33, 2561-2568. https://doi.org/10.1016/S0043-1354(98)00476-X

[14] Mansouri, L., Sabelfeld, M., Geissen, S.U. and Bousselmi, L. (2015) Catalysed Ozonation for Removal of an Endocrine-Disrupting Compound Using the $\mathrm{O}_{3} /$ Fenton Reagents System. Environmental Technology, 36, 1721-1730. https://doi.org/10.1080/09593330.2015.1008054

[15] Lucas, M.S. and Peres, J.A. (2009) Removal of COD from Olive Mill Wastewater by Fenton's Reagent: Kinetic Study. Journal of Hazardous Materials, 168, 1253-1259. https://doi.org/10.1016/j.jhazmat.2009.03.002

[16] Deng, Y. and Englehardt, J.D. (2006) Treatment of Landfill Leachate by the Fenton 
Process. Water Research, 40, 3683-3694.

https://doi.org/10.1016/j.watres.2006.08.009

[17] Antonio, D.C. and Roberto, S. (1994) Monitoring Aromatic Surfactants and Their Biodegradation Intermediates in Raw and Treated Sewages by Solid-Phase Extraction and Liquid Chromatography. Environmental Science and Technology, 28, 850858. https://doi.org/10.1021/es00054a016

[18] Solea, M., Maria, J. and Loapez, D.A. (2000) Estrogenicity Determination in Sewage Treatment Plants and Surface Waters from the Catalonian Area (NE Spain). Environmental Science and Technology, 34, 5076-5083.

https://doi.org/10.1021/es991335n

[19] Sun, S.P., Li, C.J., Sun, J.H., Shi, S.H., Fan, M.H. and Zhou, Q. (2009) Decolorization of An Azo Dye Orange G in Aqueous Solution by Fenton Oxidation Process: Effect of System Parameters and Kinetic Study. Journal of Hazardous Materials, 161, 1052-1057. https://doi.org/10.1016/j.jhazmat.2008.04.080

Submit or recommend next manuscript to SCIRP and we will provide best service for you:

Accepting pre-submission inquiries through Email, Facebook, LinkedIn, Twitter, etc. A wide selection of journals (inclusive of 9 subjects, more than 200 journals)

Providing 24-hour high-quality service

User-friendly online submission system

Fair and swift peer-review system

Efficient typesetting and proofreading procedure

Display of the result of downloads and visits, as well as the number of cited articles

Maximum dissemination of your research work

Submit your manuscript at: http://papersubmission.scirp.org/

Or contactajac@scirp.org 